\title{
EXPECTATIVAS PROFISSIONAIS DOS INGRESSANTES NO CURSO DE GRADUAÇÃO EM CIÊNCIAS CONTÁBEIS: UM ESTUDO EM UMA INSTITUIÇÃO DE ENSINO SUPERIOR
}

\section{PROFESSIONAL EXPECTATIONS OF UNDERGRADUATE STUDENTS IN ACCOUNTING: A STUDY IN AN HIGHER EDUCATION INSTITUTION}

0 artigo foi aprovado e apresentado no XIX USP International Conference in Accounting, realizado de 24/07 a 26/07 de 2019, em São Paulo (SP)

\section{RESUMO}

$\mathrm{Na}$ área de contabilidade, a demanda é por profissionais qualificados, providos de habilidades, conhecimentos específicos e que estejam preparados para enfrentar as questões envolvendo as atribuições da área em que atuam, podendo gerar a expectativa de uma boa remuneração, estabilidade e segurança no emprego. Diante disso, este estudo teve como objetivo investigar quais são as expectativas profissionais dos alunos que ingressaram, em 2018, no curso de graduação em Ciências Contábeis de uma Instituição de Ensino Superior pública. Neste sentido, espera-se que identificar as expectativas profissionais dos estudantes ingressantes possa colaborar com a instituição e seus docentes, pois conhecendo as pretensões dos estudantes, é possível realizar uma adequação nos projetos pedagógicos, tornando-os mais adequados ao perfil desses discentes e buscando atender melhor aos seus interesses. Trata-se de uma investigação descritiva, do tipo survey, com abordagem quantitativa, sendo utilizada na análise a estatística descritiva e a análise fatorial exploratória. Dessa forma, os resultados revelam que a maioria dos alunos é do gênero feminino e tem até 25 anos de idade. Suas expectativas indicam interesse em prestar concursos públicos e atuar na área financeira e de auditoria, tendo pouco interesse nas áreas trabalhista e de contabilidade do agronegócio. Sobre as recompensas profissionais esperadas, grande parte dos estudantes deseja ganhar um bom salário e demais beneficios. Já por meio da análise fatorial, observou-se que as expectativas profissionais dos estudantes se relacionam com a atuação em empresas de terceiros, na condição de profissional liberal e com cargos que proporcionem status e estabilidade.

Palavras chave: Expectativas profissionais, Estudante de Ciências Contábeis, Perfil do ingressante, Recompensas profissionais.

\begin{abstract}
In the accounting area, the demand is for qualified professionals, provided with skills, specific knowledge and prepared to face the issues involving the attributions of the area in which they operate, which can generate the expectation of good remuneration, stability and job security. Given this, this study aimed to investigate what are the professional expectations of students who entered in 2018, in the undergraduate course in Accounting, from a public higher education institution, based on Expectation Theory. In this sense, it is hoped that identifying the professional expectations of incoming students can collaborate with the institution and its teachers, because knowing the students 'pretensions, it is possible to adjust the pedagogical projects, making them more appropriate to the students' profile and seeking to meet best for your interests. This is a descriptive survey, with a quantitative approach, using descriptive statistics and exploratory factor analysis. The results reveal that most students are female and up to 25 years old. Their expectations indicate an interest in public procurement, financial and auditing, and little interest in labor and agribusiness accounting. Regarding the expected professional rewards, most students want to earn a good salary and other benefits. Through factor analysis, it was observed that students' professional expectations are related to their performance in third-party companies, as liberal professionals and with positions that provide status and stability.
\end{abstract}

Keywords: Professional Expectations, Accounting Student, Newcomer Profile, Professional Rewards.

\section{Deise Ferreira}

Especialista em Ciências Contábeis pela Universidade Federal do Rio Grande (FURG) Especialista em Controladoria e Finanças pelo Centro Universitário Internacional (Uninter). Graduada em Ciências Contábeis pela Universidade Federal do Rio Grande (FURG). Mestranda em Ciências Contábeis pela Universidade Federal do Rio Grande (FURG). Contato: Rua Jorge Carvalho de Campos Moraes, 354, Cassino, Rio Grande, RS, CEP: 96.209-230. E-mail: ferreira_deise@hotmail.com

\section{Alexandre Costa Quintana}

Doutor em Controladoria e Contabilidade pela Universidade de São Paulo (USP). Mestre em Administração pela Universidade Federal de Santa Catarina (UFSC). Graduado em Ciências Contábeis pela Universidade Federal do Rio Grande (FURG). Docente dos cursos de graduação e pós-graduação de Ciências Contábeis na Universidade Federal do Rio Grande (FURG). Contato: Rua Chefe Carlos de Araújo, 166, Cassino, Rio Grande, RS, CEP: 96.206-210. E-mail: professorquintana@hotmail.com

\section{Ana Paula Capuano da Cruz} Doutora em Controladoria e Contabilidade pela Universidade de São Paulo (USP). Mestre em Contabilidade pela Universidade Federal do Paraná (UFPR). Especialista e Graduada em Ciências Contábeis pela Universidade Federal do Rio Grande (FURG). Docente dos cursos de graduação e pósgraduação de Ciências Contábeis na Universidade Federal do Rio Grande (FURG). Contato: Rua Rua Karlo Harazim, 83, Vila São Jorge, Rio Grande, RS, CEP: 96.203-210. E-mail: anapaulacapuanocruz@ hotmail.com

\section{Débora Gomes de Gomes \\ Pós-Doutora em Ciências Contábeis pela Universidade do Vale do Rio dos Sinos (UNISINOS). Doutora em Ciências Contábeis e Administração pela Universidade Regional de Blumenau (FURB). Mestre em Ciências Contábeis pela Universidade do Vale do Rio dos Sinos (UNISINOS). Graduada em Ciências Contábeis pela Universidade Católica de Pelotas (UCPEL). Docente dos cursos de graduação e pós-graduação de Ciências Contábeis na Universidade Federal do Rio Grande (FURG). Contato: Rua Karlo Harazim, 71, Vila São Jorge, Rio Grande, RS, CEP: 96.203-210. E-mail: debora_furg@yahoo.com.br}




\section{INTRODUÇÃO}

No Brasil, a área da contabilidade é bastante ampla e proporciona muitas oportunidades de carreira, permitindo que haja boas perspectivas profissionais com diversas alternativas de atuação (Scarpin \& Almeida, 2010). Marion e Santos (2000, p. 3), afirmam que "num sentido prático, a primeira maneira de avaliar as perspectivas de uma atividade profissional é saber se existem bons empregos nesta área”. De acordo com os autores, as pesquisas apontam que a área contábil além de oferecer ao profissional uma certa garantia da existência de empregos, também proporciona uma remuneração significativa, em comparação a outras profissões (Marion \& Santos, 2000). Dentre as várias opções de atuação, além da função de contador, o profissional contábil pode exercer cargos de consultor, assessor, auditor interno e externo, perito, controller, professor e etc. Sendo que tais atividades podem ser realizadas em empresas privadas, no serviço público e na condição de autônomo ou profissional liberal (Resolução CFC, 1993).

Apesar das amplas oportunidades de carreira que o graduado em Ciências Contábeis tem, em virtude do constante processo de mudanças, principalmente no que diz respeito à legislação e pelas novas regras que surgem a cada dia, o mercado de trabalho busca profissionais qualificados, providos de habilidades, conhecimentos específicos e que estejam preparados para enfrentar as questões que envolvem as atribuições da área em que atuam (Pires, 2008; Panucci Filho, 2011; Santos \& Almeida, 2017). Essa necessidade provoca grande influência na escolha da profissão, assim como a expectativa de uma boa remuneração, estabilidade e segurança no emprego (Marion, \& Santos, 2000; Bomtempo, 2005; Panucci Filho, 2011; Peleias, Nunes, \& Carvalho, 2017).

Dados do Censo da Educação Superior realizado no ano de 2016, pelo Instituto Nacional de Estudos e Pesquisas Educacionais Anísio Teixeira - INEP, demonstram que, entre o ano de 2009 a 2016, mais de 933 mil estudantes ingressaram no curso de Ciências Contábeis, em instituições brasileiras (INEP, 2016). Devido ao número de novos estudantes que ingressam no curso, as Instituições de Ensino Superior (IES) enfrentam o desafio de acompanhar os ingressantes, principalmente no que diz respeito às suas escolhas e expectativas profissionais, pois com as inúmeras possibilidades de atuação, há uma grande dificuldade na definição das atividades que o futuro egresso deseja exercer (Peleias, Guimarães, Silva, \& Ornelas, 2008; Schmidt, Ott, Santos, \& Fernandes, 2012; Miranda, Araujo, \& Miranda., 2015).

$\mathrm{Na}$ literatura brasileira, utilizando como meio de busca o portal de periódicos CAPES/MEC e a base SPELL, foram encontrados poucos trabalhos que investigaram as expectativas dos estudantes ingressantes do curso de Ciências Contábeis, que é o caso dos estudos de Miranda et al. (2015) e Lagioia, Santiago, Gomes, e Ribeiro Filho (2007), sendo que nesse os autores utilizaram como amostra os alunos que estavam cursando do $1^{\circ}$ ao $9^{\circ}$ semestre, verificando as expectativas que eles tinham quando ingressaram no curso. Nos estudos de Panucci Filho (2011), Schmidt et al. (2012) e Marques, Dias e Silva (2016) apesar de terem sido verificadas as expectativas e perspectivas profissionais dos estudantes, a pesquisa não foi realizada com os ingressantes. Já Peleias et al. (2017) utilizaram como amostra os ingressantes, porém buscaram identificar os fatores determinantes na escolha do curso, em que foram citadas pelos estudantes algumas possibilidades de carreira futura desejadas por eles. Nesse sentido, torna-se relevante um estudo sobre as expectativas profissionais dos alunos que ingressam no curso de Ciências Contábeis.

Diante o exposto, formulou-se e buscou-se a resposta à seguinte questão de pesquisa: Quais são as expectativas profissionais dos alunos que ingressaram, em 2018, no curso de graduação em Ciências Contábeis de uma Instituição de Ensino Superior pública? Sendo assim, o objetivo geral do estudo é investigar junto aos alunos que ingressaram no curso de graduação em Ciências Contábeis de uma Instituição de Ensino Superior pública, no ano de 2018, quais são suas expectativas profissionais.

Justifica-se a realização deste estudo em função das dificuldades que as instituições têm para conhecer os alunos ingressantes e os seus intentos profissionais, uma vez que a área contábil proporciona um amplo campo de atuação (Miranda et al., 2015; Peleias et al., 2017).

Dessa forma, espera-se que a identificação das expectativas profissionais dos alunos ingressantes possa contribuir com as IES, coordenadores de curso, Conselhos Regionais de Contabilidade, sindicatos profissionais, colégios e outros agentes interessados na área e na divulgação da carreira contábil, pois o conhecimento da profissão pode fazer com que a escolha pelo curso seja feita de forma mais consciente, visto que muitos estudantes escolhem cursar Ciências Contábeis pelo número elevado de vagas disponíveis. Além disso, os resultados encontrados podem colaborar com a universidade e com o seu corpo docente, em razão de que, ao conhecer as pretensões dos alunos, é possível realizar uma adequação nos projetos pedagógicos, tornando-os mais próximos do perfil dos estudantes e buscando atender melhor aos seus interesses. Tal fato se dá uma vez que a formação recebida pelo aluno, durante sua trajetória no curso escolhido, poderá influenciar as suas expectativas, escolhas profissionais e satisfação pelo curso e instituição de ensino (Lagioia et al., 2007; Peleias \& Nunes, 2015; Miranda et al., 2015; Peleias et al., 2017). 


\section{REVISÃO DA LITERATURA}

Esta seção trabalha com o referencial da Literatura sobre o tema, com o propósito de gerar subsídios para o andamento da pesquisa, e são eles: a profissão contábil e as expectativas profissionais.

\subsection{A Profissão Contábil}

A contabilidade é apontada como um sistema de informação, sendo considerada uma ferramenta essencial para auxiliar a administração da empresa. É por meio dela que os dados econômicos são coletados, mensurados monetariamente, registrados e processados em forma de relatórios, produzindo informações úteis aos seus usuários e contribuindo no processo de tomada de decisão (Marion, 2008). Pelo fato da contabilidade ser direcionada à gestão da empresa e à tomada de decisão por parte dos sócios, credores, investidores e outros tipos de usuários, ela deve ser vista de forma abrangente (Pinheiro, 2008). Sendo assim, Marion (2008) destaca que "A contabilidade é a linguagem dos negócios." (p. 24)

De acordo com Lagioia et al. (2007) a contabilidade por ser interligada com a administração, economia, estatística e outras disciplinas relacionadas, prepara o estudante para ser um profissional que está apto a exercer uma diversidade de funções no mercado de trabalho. A esse respeito, Marion (2008) ressalta que "A Contabilidade é uma das áreas que mais proporciona oportunidades para o profissional." (p. 27)

O profissional de contabilidade tem a possibilidade de atuar em empresas privadas, no ensino e em órgãos públicos, exercendo diversas funções que, muitas vezes, por terem relação entre elas, permite a atuação em mais de um ramo. Também é possível atuar de forma independente, em que alguns profissionais se tornam empresários da área contábil (Resolução CFC, 1983; Marion, 2008; Panucci Filho, 2010). Na Tabela 1 são expostas algumas funções que podem ser exercidas pelo graduado em Ciências Contábeis.

Tabela 1 - Alternativas de atuação do profissional contábil

\begin{tabular}{l|l}
\hline Campo de Atuação & Função \\
\hline Empresa & $\begin{array}{l}\text { Contador Geral, Auditor Interno, Controller, Analista Financeiro, Cargos Administrativos, Planejador } \\
\text { Tributário, entre outras. }\end{array}$ \\
Independente (Autônomo) & $\begin{array}{l}\text { Auditor Independente, Perito Contábil, Empresário Contábil, Consultor Contábil, entre outras. } \\
\text { Ensino }\end{array}$ \\
Órgão Público & Contador Público, Fiscal de Tributos, Controlador de Arrecadação, entre outras. \\
\hline
\end{tabular}

Nota: Fonte: Adaptado de Marion (2008).

Das diversas alternativas profissionais existentes na área contábil, há preferência em exercer o cargo de Contador, sendo que, para exercê-lo, o bacharel em Ciências Contábeis necessita ser aprovado no exame de suficiência, que é realizado pelo Conselho Federal de Contabilidade, obtendo assim o seu registro profissional junto ao Conselho de sua região (Peleias \& Nunes, 2015; Resolução CFC, 2015).

$\mathrm{Na}$ área pública o contador tem função específica, pois de acordo com a Lei Complementar n ${ }^{\circ} 101 / 2000$ - Lei de Responsabilidade Fiscal, há necessidade de ação planejada e transparente, objetivando a prevenção de riscos e correção de possíveis desvios que podem afetar o equilíbrio das contas públicas. Desse modo, o contador deve realizar suas atividades em conformidade com o estabelecido na Lei (Lei Complementar $n^{\circ} 101 / 2000$ ), a respeito disso, Pinheiro (2008) diz que cabe ao contador o "assessoramento sobre a aplicação dos gastos públicos e gestor das informações contábeis contidas no orçamento, fazendo com que os princípios legais sejam cumpridos.” (p. 24-25)

Por se tratar de uma profissão com amplitude de atuação, o Conselho Federal de Contabilidade, por intermédio da Resolução CFC n 560/1983, alterada pela Resolução CFC nº 898/2001, definiu as atribuições que devem ser exercidas exclusivamente pelo profissional contábil e as que podem ser desempenhadas por outros profissionais, tais como: advogados, administradores, economistas, engenheiros entre outros, chamadas de atividades compartilhadas (Resolução CFC, 1983, 2001). Das atribuições privativas definidas pelo CFC, a Tabela 2 apresenta algumas delas. 
Tabela 2 - Atividades privativas e compartilhadas

\section{ATIVIDADES PRIVATIVAS DO PROFISSIONAL CONTÁBIL}

- avaliação de acervos patrimoniais e verificação de haveres e obrigações, para quaisquer finalidades, inclusive de natureza fiscal.

- apuração do valor patrimonial de participações, quotas ou ações.

- concepção dos planos de determinação das taxas de depreciação e exaustão dos bens materiais e dos de amortização dos valores imateriais, inclusive de valores diferidos.

- revisões de balanços, contas ou quaisquer demonstrações ou registros contábeis.

- fiscalização tributária que requeira exame ou interpretação de peças contábeis de qualquer natureza.

- magistério das disciplinas compreendidas na Contabilidade, em qualquer nível de ensino, inclusive no de pós-graduação.

Nota: Fonte: Adaptado da Resolução do CFC (CFC, 1983, 2001).

Já como atividades compartilhadas definidas pelo Conselho Federal de Contabilidade, ou seja, aquelas que não são exclusivas do profissional de contabilidade, a Tabela 3 apresenta alguns exemplos.

\section{Tabela 3 - Atividades compartilhadas}

\section{ATIVIDADES COMPARTILHADAS}

- elaboração de projetos e estudos sobre operações financeiras e qualquer natureza, inclusive de debêntures, "leasing” e "lease-back".

- análise de sistemas de seguros e de fundos de benefícios.

- concepção, redação e encaminhamento, ao Registro Público, de contratos, alterações contratuais, atas, estatutos e outros atos das sociedades civis e comerciais.

- elaboração de planos técnicos de financiamento e amortização de empréstimos, incluídos no campo da matemática financeira.

- elaboração e análise de projetos, inclusive quanto à viabilidade econômica.

- execução de tarefas no setor financeiro, tanto na área pública quanto privada.

- elaboração de cálculos, análises e interpretação de amostragens aleatórias ou probabilísticas.

Nota: Fonte: Adaptado da Resolução do CFC (CFC, 1983, 2001).

Ainda que o CFC estabeleça que o magistério contábil seja uma atividade exclusiva do contador, Pires (2008) destaca que o conselho não tem autoridade para impedir que outros profissionais exerçam esta atividade. Visto que, em muitos casos, o ensino contábil é praticado por profissionais não graduados em Ciências Contábeis, mas que possuem mestrado ou doutorado na área (Pires, 2008).

Diante do exposto sobre a profissão contábil, é possível afirmar que o estudante que escolhe o curso de graduação em Ciências Contábeis poderá seguir vários caminhos, no que se referem a sua profissão, devido à abundância de possibilidades de atuação do profissional de contabilidade (Panucci Filho, 2011).

\subsection{Expectativas Profissionais}

Entende-se por expectativa a força do desejo para que os objetivos individuais sejam atingidos, a expressão "expectativa" tem um sentido de visão no futuro e relaciona-se com os projetos dos indivíduos, tanto pessoais, quanto profissionais (Reis Neto \& Marques, 2003; Simões, 2008). Para Panucci Filho (2010) "os indivíduos de maneira geral, movidos por perspectivas, procuram suprir necessidades elementares, em muitos casos a sobrevivência” (p. 30).

Segundo Lobos (1975) “o conceito de expectativa refere-se à percepção que o indivíduo tem das mudanças em seu nível de desempenho” (p. 21). Para Simões (2008) só existe expectativa se houver uma atitude reflexiva. Quanto à criação das expectativas, Simões (2008) expõe que, em função da adoção de valores, origem sócio-econômica e ambiente em que vivem, os indivíduos criam expectativas e investem em um projeto profissional e de vida, estabelecendo estratégias e utilizando todas as ferramentas disponíveis para a concretização dos seus objetivos.

Victor Vroom desenvolveu no ano de 1964 a teoria da expectativa, que é uma das teorias a respeito da motivação mais aceitas na Literatura (Freitas \& Freire, 2007). Ela é considerada uma teoria de processo que estuda as ligações entre as variáveis dinâmicas, tais como: clima, estrutura disponível e oportunidades de tomada de decisão, dentre outras, 
explicando assim, o comportamento dos indivíduos no trabalho (Castro, Nishimura, Silva, Madureira, \& Casado, 2007; Robbins, Judge, \& Sobral, 2010).

Sobre a teoria da expectativa, Robbins (2005) salienta que a mesma defende "que a força da tendência para agir de determinada maneira depende da força da expectativa de que esta ação trará certo resultado, e da atração que este resultado exerce sobre o indivíduo" (p. 148). Para o autor, a essência da teoria da expectativa é entender quais são os objetivos dos indivíduos e as relações entre esforço, desempenho, recompensa e alcance de metas pessoais (Robbins, 2005).

Figura 1- Teoria da Expectativa

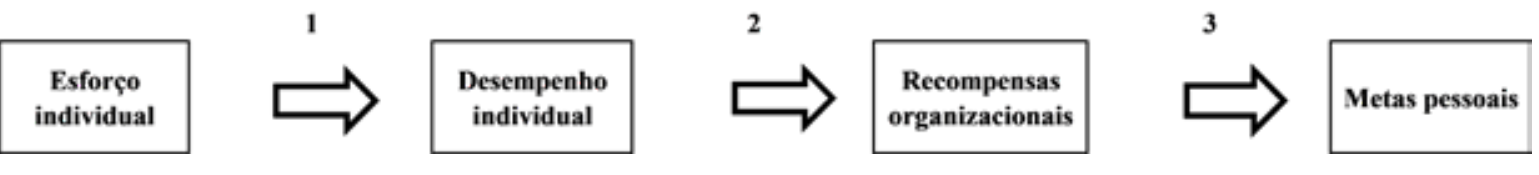

Fonte: Adaptado de Robbins (2005).

Maximiano (1997) destaca que a teoria da expectativa busca explicar qual é o efeito que a recompensa tem sobre a vontade das pessoas em executar algum tipo de esforço. Sob o mesmo ponto de vista, Vergara (2003) diz que se um colaborador deseja receber elogios de seu chefe e acredita que trabalhar após o expediente fará com que isso aconteça, então ele trabalhará. No contexto acadêmico, Maximiano (1997) exemplifica a teoria da expectativa pelo estudante que pretende ingressar na universidade e, para isso, necessita primeiramente ser aprovado no processo seletivo da instituição desejada, sendo que, para conseguir a aprovação, será necessário estabelecer um intenso programa de estudo. Nesse caso, ingressar na universidade é considerado a recompensa, obter a aprovação no processo seletivo, o desempenho e o estudo realizado, ou seja, o esforço (Maximiano, 1997).

Também é de suma importância salientar que ao tratar da teoria da expectativa, muito se fala sobre recompensas, Hipólito (2004) considera recompensa aquilo que é concedido aos colaboradores em troca da realização de tarefas de modo que, segundo Dutra (2009), as recompensas podem ser apontadas como o atendimento das expectativas e necessidades dos indivíduos.

Existem duas maneiras de recompensar um indivíduo pela execução de alguma atividade: as financeiras, que estão relacionadas ao dinheiro e as não financeiras, que se referem a fatores que influenciam a satisfação do indivíduo (Hipólito, 2004; Alves, Silva \& Oliveira, 2017). São exemplos de recompensas financeiras: salários e demais benefícios, prêmio individual pelo desempenho, participação nos lucros, etc. E como exemplos de recompensas não financeiras pode-se citar: reconhecimento profissional, crescimento pessoal, estabilidade no emprego, entre outros (Freitas \& Freire, 2007; Alves et al., 2017).

Diante ao exposto, é possível dizer que, tanto no ambiente profissional, quanto no meio acadêmico, um indivíduo sente-se motivado em fazer algo quando acredita que terá um bom resultado e obterá recompensas, monetárias ou não, que irão satisfazer seus intentos pessoais. Sendo que, a eficácia da recompensa está diretamente vinculada à necessidade do indivíduo que é representada por seu objetivo pessoal (Maximiano, 1997; Robbins, 2005; Alves et al., 2017).

$\mathrm{Na}$ tentativa de avaliar as percepções e perspectivas dos estudantes nos últimos anos, algumas pesquisas têm sido realizadas, (Lagioia et al., 2007). Dessa forma, cabe destacar alguns estudos, utilizados na presente pesquisa, em que os autores buscaram conhecer as perspectivas dos estudantes. Nesse sentido, Panucci Filho (2010) apontou em sua dissertação que a maior parte dos estudantes tem como objetivo progredir profissionalmente, aumentar sua renda e ampliar seus conhecimentos para melhorar seu nível de educação.

Buscando conhecer as expectativas dos discentes, Lagioia et al. (2007) realizaram um estudo, junto aos alunos que estavam cursando do $1^{\circ}$ ao $9^{\circ}$ semestre do curso de Ciências Contábeis, em que o objetivo era examinar quais as suas expectativas profissionais, quando ingressaram na universidade, bem como verificar se essas expectativas foram mantidas ou modificadas no decorrer do curso. No que tange às expectativas iniciais, os autores constataram que mais de $40 \%$ dos estudantes pesquisados responderam que, ao escolher o curso de Ciências Contábeis, tinham como expectativa passar em um concurso público e 36,70\% manifestaram que a intenção era de trabalhar em empresas de terceiros, ocupando o cargo de contador ou auditor.

Na pesquisa desenvolvida por Miranda et al. (2015) foi analisado o perfil e as expectativas dos ingressantes do curso de Ciências Contábeis e os autores concluíram que a maioria dos alunos tem como expectativa profissional futura ser empregado de grandes empresas, proprietário de um escritório de contabilidade e atuar na área contábil do setor público. Sendo que, uma pequena parte dos alunos tem interesse em exercer funções fora da área contábil no setor público.

Quanto à área de atuação, Miranda et al. (2015) apuraram que existe uma preferência pelas áreas de contabilidade geral/financeira, fiscal/tributária, auditoria e controladoria. No estudo de Marques, Dias e Silva (2016), os autores destacaram a auditoria e a perícia como áreas de maior interesse, por parte dos estudantes, e no que diz respeito às áreas de menor interesse, $50 \%$ dos respondentes indicaram ensino e pesquisa em contabilidade e contabilidade do agronegócio. No entanto, cabe ressaltar que a pesquisa foi realizada com alunos que estavam cursando o $2^{\circ}, 5^{\circ}$ e $8^{\circ}$ semestre e não somente com ingressantes. 


\section{METODOLOGIA}

Com o propósito de verificar as expectativas profissionais dos alunos que ingressaram em 2018, no curso de graduação em Ciências Contábeis de uma IES pública, foi realizada uma pesquisa descritiva, pois segundo Gil (2002) estudos descritivos têm como objetivo principal descrever as características de uma determinada população ou fenômeno, ou estabelecer relações entre as variáveis da pesquisa. Em relação à coleta de dados, a tipologia adotada foi o levantamento, ou survey, visto que, buscou-se obter informações de um grupo de indivíduos, interrogando-os diretamente sobre os dados que se pretende conhecer (Gil, 2002; Silveira \& Córdova, 2009). Já para a análise e interpretação dos dados coletados, foi utilizada a abordagem quantitativa, uma vez que essa abordagem é caracterizada pelo uso de instrumentos estatísticos (Raupp \& Beuren, 2013).

A população alvo da pesquisa foi definida pela acessibilidade e é composta pelos estudantes que ingressaram no curso de graduação em Ciências Contábeis de uma Instituição de Ensino Superior pública em 2018. Na instituição, atualmente, são disponibilizadas 100 vagas, com ingresso anual, por meio do Sistema de Seleção Unificada - SISU e o curso é oferecido no turno da noite, na modalidade presencial e com a duração mínima de oito semestres letivos em razão do regime de matricula semestral (IES, 2018).

O instrumento de pesquisa utilizado foi um questionário dividido em dois blocos, o primeiro bloco contém 12 questões fechadas sobre o perfil do estudante, extraídas dos questionários de Panucci Filho (2010) e Nunes (2014). O segundo bloco é composto de 30 assertivas, com as respostas obedecendo a uma escala do tipo Likert de cinco pontos, variando de "discordo totalmente" até "concordo totalmente", os quais, de acordo com Brandalise e Bertolini (2013), requerem que os participantes da pesquisa assinalem seus níveis de concordância ou discordância com as afirmativas que se referem às atitudes que estão sendo verificadas. Do total das assertivas pertencentes ao segundo bloco, 13 são a respeito das expectativas profissionais dos estudantes e 7 acerca das áreas de atuação que os interessam, sendo todas retiradas e elaboradas a partir dos estudos de Lagioia et al. (2007), Panucci Filho (2010), Schmidt et al. (2012), Miranda et al. (2015) e Marques et al. (2016). As demais são referentes às recompensas profissionais esperadas pelos estudantes e foram baseadas nos resultados dos estudos desenvolvidos por Freitas e Freire (2007), Costa, Salles e Fontes Filho (2010) e Alves et al. (2017).

Tendo em vista o objetivo de investigar os alunos ingressantes no ano de 2018 e o fato do instrumento de pesquisa ter sido aplicado no segundo semeste letivo, foi escolhida a disciplina de Contabilidade Intermediária, na qual estavam matriculados os ingressantes no primeiro semestre do mesmo ano. Para o pré-teste, que teve a finalidade de testar e validar o questionário, devido ao ingresso anual, foi escolhida a turma de Contabilidade Básica II, em que a maioria dos estudantes ingressaram no curso no segundo semestre de 2017. Cabe ressaltar que o curso passou por mudanças recentemente, tanto no currículo, quanto no ingresso, sendo que até o ano de 2017 o ingresso de novos alunos ocorria semestralmente.

O pré-teste foi aplicado no mês de outubro de 2018, de forma presencial, junto aos 27 alunos que estavam presentes na aula da disciplina de Contabilidade Básica II, pertencente ao currículo antigo do curso. Em um segundo momento, no mesmo mês, após a correção dos equívocos constatados na fase de pré-teste, o questionário foi aplicado novamente, também de forma presencial, porém com os alunos da disciplina de Contabilidade Intermediária, que faz parte do currículo novo. Na ocasião, dos 64 alunos matriculados na disciplina, estavam presentes 57 e todos colaboraram com a pesquisa, os demais não foram localizados. Em virtude de todos os questionários terem sido utilizados, a amostra da pesquisa foi composta pelos estudantes que responderam o instrumento de pesquisa.

Quanto à análise dos dados, inicialmente foi realizada a análise descritiva dos resultados de todas as questões e assertivas contidas no questionário. Posteriormente, utilizando as respostas referentes às expectativas profissionais dos estudantes, foi executado com o auxílio do software IBM SPSS statistics $23 \AA$, o teste estatístico chamado análise fatorial exploratória, sendo escolhido o método de extração Análise de Componente Principal e o método de rotação Varimax com Normalização de Kaiser. Esse teste tem como intuito principal simplificar a informação que é trazida em diversas variáveis em um conjunto de dados menor denominados de fatores, com mínima perda de informação, permitindo avaliar o quanto cada fator está associado a cada variável (Fávero, Belfiore, Silva, \& Chan, 2009; Hair Jr., Black, Babin, Anderson, \& Tatham, 2009).

\section{APRESENTAÇÃO E ANÁLISE DOS DADOS}

A análise descritiva das respostas das doze questões sobre o perfil dos ingressantes aponta que $58 \%$ da amostra é composta por estudantes do gênero feminino e $42 \%$ do gênero masculino. Na pesquisa realizada por Miranda et al. (2015) tal caracteristíca também é observada, porém, em estudo anterior elaborado por Lagioia et al. (2007) os resultados indicam que a maior parte dos estudantes é do sexo masculino. Tal diferença no gênero, pode indicar que nos últimos anos ocorreu uma mudança no perfil daqueles que procuram o curso, em virtude das transformações ocorridas na área profissional, visto que as mulheres vêm ocupando maior espaço no mercado de trabalho, que anteriormente era predominantemente ocupado por homens (Panucci Filho, 2011).

Em relação à faixa etária, $70 \%$ possuem até 25 anos de idade, 25\% entre 26 e 35 anos e 5\% entre 36 e 45 anos. Quanto ao estado civil, observou-se uma predominância de estudantes solteiros (74\%).

No que se refere ao ensino médio dos respondentes, foi questionado o tipo de escola frequentada, a modalidade de ensino e o ano de conclusão. Os resultados encontrados estão apresentados na Tabela 4. 
Tabela 4 - Ensino Médio

\begin{tabular}{l|c}
\hline \multicolumn{2}{c}{ Você cursou em: } \\
\hline Escola pública & $81 \%$ \\
Escola particular & $11 \%$ \\
Ambas & $8 \%$ \\
\hline \multicolumn{2}{c}{ Você frequentou: } \\
\hline Ensino médio regular & $84 \%$ \\
EJA (supletivo) & $4 \%$ \\
Cursos técnicos & $12 \%$ \\
\hline \multicolumn{2}{c}{ Em que ano você concluiu? } \\
\hline Até 2000 & $7 \%$ \\
Entre 2001 e 2016 & $75 \%$ \\
Em 2017 & $18 \%$ \\
\hline
\end{tabular}

Nota: Fonte: Dados da pesquisa.

A maioria dos estudantes pesquisados é egressa do ensino público (81\%), concluiu o curso entre o ano de $2001 \mathrm{e}$ 2017 (93\%) e cursou o Ensino Médio na modalidade regular (84\%). Salienta-se que dos $12 \%$ que frequentaram cursos técnicos, $5 \%$ realizaram o curso Técnico em Contabilidade.

Também foi questionado se os estudantes haviam iniciado algum outro curso superior, verificando-se que $61 \%$ estão realizando um curso superior pela primeira vez e 39\% já iniciaram, sendo que apenas $12 \%$ conseguiram concluir. Além disso, foi constatado que mais de $50 \%$ dos estudantes não participaram de curso preparatório para o ENEM.

Quanto à atividade remunerada, a maior parte dos estudantes (68\%) trabalha em atividade remunerada, sendo $40 \%$ em área não relacionada com contabilidade e $18 \%$ em atividade relacionada à contabilidade, os demais (42\%) não trabalham. Resultado que difere do encontrado no estudo de Peleias et al. (2017), em que mais de $50 \%$ dos estudantes trabalhavam em atividade relacionada à contabilidade quando ingressaram no curso e apenas $20 \%$ não trabalhavam em atividade remunerada.

A respeito da renda familiar, houve um equilibrio nos resultados, com exceção daqueles que possuem renda acima de 10 salários mínimos, conforme demonstrado na Figura 2.

Figura 2 - Renda familiar

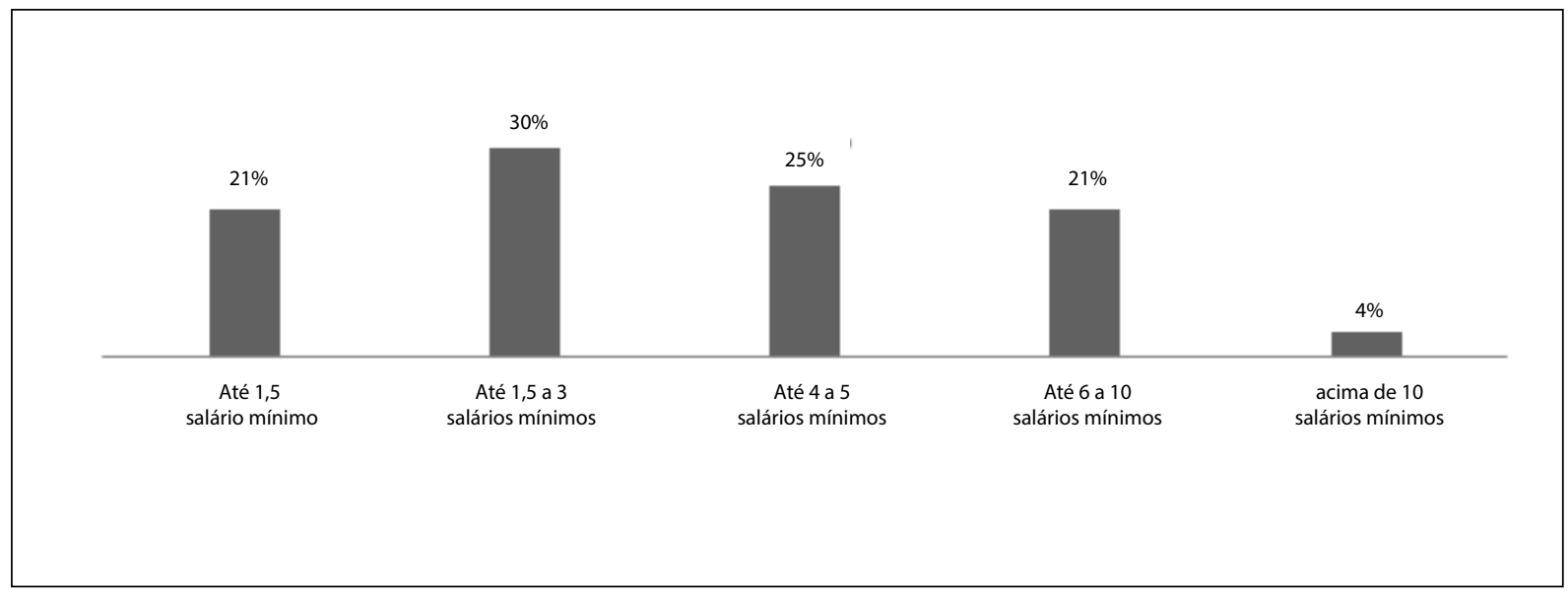

Fonte: Dados da pesquisa.

Indagados sobre a escolaridade dos pais, todos os estudantes informaram a escolaridade da mãe e apenas $5 \%$ dos estudantes não souberam informar a escolaridade do pai. Os resultados estão apresentados na Figura 3. 
Figura 3 - Escolaridade dos pais

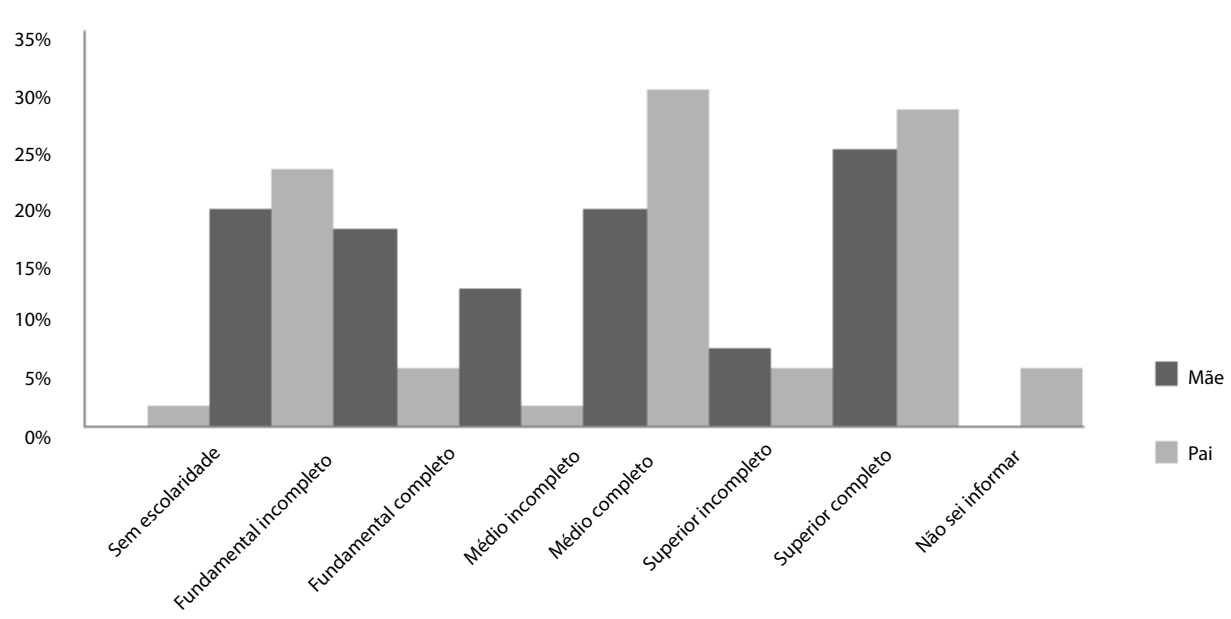

Fonte: Dados da pesquisa.

Conforme observado na Figura 3, em relação à escolaridade da mãe, a maior parte dos estudantes informou que ela possui ensino superior completo (25\%), já sobre a escolaridade do pai, $30 \%$ responderam que ele concluiu até o Ensino Médio e $28 \%$ que ele possui Ensino Superior completo.

A respeito das trinta assertivas do segundo bloco, em que se buscou verificar as expectativas profissionais dos ingressantes, áreas de atuação de maior e menor interesse e também identificar quais as recompensas profissionais esperadas por eles, as frequências obtidas nas respostas dos estudantes são apresentadas a seguir.

Em relação às expectativas profissionais, foram indicadas algumas possibilidades de atuação. Salienta-se que nas afirmativas "montar um escritório de contabilidade", "atuar como controller", "ser contador em empresa privada de pequeno/médio porte" e "ainda não sei o que fazer quando concluir o curso" houve $2 \%$ de abstenção em cada uma delas. A Tabela 5 apresenta os resultados encontrados.

Tabela 5 - Expectativas Profissionais

\begin{tabular}{|c|c|c|c|c|c|}
\hline & $\begin{array}{l}\text { Discordo } \\
\text { Totalmente }\end{array}$ & Discordo & Indiferente & Concordo & $\begin{array}{l}\text { Concordo } \\
\text { Totalmente }\end{array}$ \\
\hline Concurso na área contábil & $2 \%$ & $2 \%$ & $4 \%$ & $21 \%$ & $72 \%$ \\
\hline Concurso em qualquer área & $12 \%$ & $12 \%$ & $14 \%$ & $37 \%$ & $25 \%$ \\
\hline Montar um escritório de contabilidade & $12 \%$ & $14 \%$ & $40 \%$ & $19 \%$ & $12 \%$ \\
\hline $\begin{array}{l}\text { Atuar no ensino, como professor ou } \\
\text { pesquisador da área contábil }\end{array}$ & $37 \%$ & $21 \%$ & $11 \%$ & $16 \%$ & $16 \%$ \\
\hline Conduzir os negócios da família & $35 \%$ & $11 \%$ & $25 \%$ & $18 \%$ & $12 \%$ \\
\hline Atuar como consultor contábil & $12 \%$ & $4 \%$ & $33 \%$ & $39 \%$ & $12 \%$ \\
\hline Atuar como perito contábil & $11 \%$ & $5 \%$ & $25 \%$ & $30 \%$ & $30 \%$ \\
\hline Atuar como controller & $7 \%$ & $4 \%$ & $54 \%$ & $25 \%$ & $9 \%$ \\
\hline Atuar como auditor interno/externo & $9 \%$ & $5 \%$ & $28 \%$ & $37 \%$ & $21 \%$ \\
\hline $\begin{array}{l}\text { Contador em empresa privada de } \\
\text { pequeno/médio porte }\end{array}$ & $4 \%$ & $12 \%$ & $37 \%$ & $32 \%$ & $14 \%$ \\
\hline $\begin{array}{l}\text { Contador em empresa privada de } \\
\text { grande porte }\end{array}$ & $2 \%$ & $5 \%$ & $35 \%$ & $33 \%$ & $23 \%$ \\
\hline Não quero trabalhar na área contábil & $79 \%$ & $14 \%$ & $4 \%$ & $4 \%$ & $0 \%$ \\
\hline $\begin{array}{l}\text { Ainda não sei o que fazer quando } \\
\text { concluir o curso }\end{array}$ & $44 \%$ & $18 \%$ & $14 \%$ & $14 \%$ & $9 \%$ \\
\hline
\end{tabular}

Nota: Fonte: Dados da pesquisa. 
Utilizando os pontos "concordo" e "concordo totalmente", pode-se dizer que há uma preferência em ingressar na carreira pública, visto que, $93 \%$ dos estudantes pretendem prestar concurso na área contábil e $62 \%$ em qualquer área. Esses resultados estão em conformidade com o levantamento feito por Miranda et al. (2015), no qual 77,6\% dos estudantes têm a intenção de atuar no setor público em cargo relacionado com contabilidade e 53,9\% serem servidores públicos em outras áreas. Os estudantes, em sua maioria, também demonstraram interesse em atuar como perito contábil (60\%) e auditor interno/externo (58\%), seguido do desejo de trabalhar como contador em empresa privada de grande porte (56\%) e como consultor contábil (51\%).

Outro dado relevante é que $54 \%$ da amostra pesquisada se mostraram indiferentes em relação à atuar como controller, talvez esse resultado se deva ao fato de os estudantes serem ingressantes e não terem conhecimento das atribuições desta profissão, visto que durante a aplicação do instrumento de pesquisa foi questionado por alguns estudantes quais atividades o controller executa. Pondera-se no entanto, embora relevantes, as expectativas profissionais dos alunos que ao longo do curso podem se alterar, especialmente com a apresentação de determinadas disciplinas e realidades que ocorrem ao final do curso, bem como descobertas de novas aptidões e habilidades. Além disso, destaca-se que ao serem questionados sobre não querer trabalhar na área contábil, 93\% dos respondentes discordaram da afirmativa, o que demonstra que a maior parte dos estudantes pretende trabalhar com contabilidade.

Com relação às áreas em que os estudantes pretendem atuar, foram listadas sete e, por meio das respostas do "concordo/concordo totalmente" e "discordo totalmente/discordo" verificou-se as áreas de maior e menor interesse. As respostas dos estudantes estão expostas na Tabela 6.

Tabela 6 - Áreas de atuação

\begin{tabular}{l|l|l|l|l|l}
\hline & $\begin{array}{l}\text { Discordo } \\
\text { Totalmente }\end{array}$ & Discordo & Indiferente & Concordo & $\begin{array}{l}\text { Concordo } \\
\text { Totalmente }\end{array}$ \\
\hline Fiscal/Tributária & $4 \%$ & $14 \%$ & $32 \%$ & $35 \%$ & $14 \%$ \\
Contabilidade de Agronegócios & $26 \%$ & $18 \%$ & $26 \%$ & $23 \%$ & $7 \%$ \\
Trabalhista & $16 \%$ & $11 \%$ & $42 \%$ & $21 \%$ & $9 \%$ \\
Controladoria & $9 \%$ & $7 \%$ & $40 \%$ & $37 \%$ & $7 \%$ \\
Auditoria & $7 \%$ & $5 \%$ & $28 \%$ & $35 \%$ & $25 \%$ \\
Contabilidade Geral & $2 \%$ & $5 \%$ & $44 \%$ & $35 \%$ & $12 \%$ \\
Financeira & $4 \%$ & $4 \%$ & $30 \%$ & $33 \%$ & $28 \%$ \\
\hline
\end{tabular}

Nota: Fonte: Dados da pesquisa.

Os resultados apontaram que há uma preferência pelas áreas Financeira (61\%) e de Auditoria (60\%), indo ao encontro dos resultados da pesquisa de Miranda et al. (2015) em que essas áreas foram escolhidas por mais de $75 \%$ dos estudantes. Já entre as áreas de menor interesse de atuação destacam-se a Contabilidade de Agronegócios e a Trabalhista, sendo cada uma escolhida por $30 \%$ dos respondentes.

No que tange as recompensas profissionais esperadas pelos estudantes, todas as afirmativas foram escolhidas por mais de $67 \%$ dos respondentes. A Tabela 7 apresenta as respostas. 
Tabela 7 - Recompensas profissionais esperadas

\begin{tabular}{l|l|l|l|l|l}
\hline & $\begin{array}{l}\text { Discordo } \\
\text { Totalmente }\end{array}$ & Discordo & Indiferente & Concordo & $\begin{array}{l}\text { Concordo } \\
\text { Totalmente }\end{array}$ \\
\hline Reconhecimento do trabalho & $2 \%$ & $2 \%$ & $5 \%$ & $23 \%$ & $68 \%$ \\
Bom salário e demais benefícios & $0 \%$ & $0 \%$ & $2 \%$ & $18 \%$ & $80 \%$ \\
Participação nos lucros & $0 \%$ & $2 \%$ & $26 \%$ & $26 \%$ & $46 \%$ \\
Estabilidade no emprego & $0 \%$ & $2 \%$ & $4 \%$ & $12 \%$ & $82 \%$ \\
Prêmios por produtividade & $2 \%$ & $0 \%$ & $70 \%$ & $52 \%$ \\
Crescimento profissional & $0 \%$ & $0 \%$ & $4 \%$ & $18 \%$ & $68 \%$ \\
Realização e crescimento pessoal & $0 \%$ & $0 \%$ & $25 \%$ & $21 \%$ & $78 \%$ \\
Status e prestígio & $0 \%$ & $5 \%$ & $19 \%$ & $26 \%$ & $49 \%$ \\
Trabalho em equipe & $2 \%$ & $7 \%$ & $26 \%$ & $42 \%$ \\
Auxílio educação & $0 \%$ & $7 \%$ & $25 \%$ & $49 \%$ \\
\hline
\end{tabular}

Nota: Fonte: Dados da pesquisa.

Ao analisar as respostas dos pontos "concordo/concordo totalmente" verifica-se que 98\% dos estudantes têm o desejo de ganhar um bom salário e demais benefícios, $96 \%$ gostariam de ter realização e crescimento profissional e $94 \%$ desejam estabilidade no emprego, resultados que diferem do encontrado no estudo de Freitas e Freire (2007), no qual a maior parte dos respondentes valoriza primeiramente a chance de crescer na carreira e o reconhecimento pelo trabalho, sendo o salário o terceiro fator mais valorizado pela amostra pesquisada.

No momento em que as recompensas financeiras são analisadas separadamente, se verifica que, com exceção do salário, as demais foram escolhidas por menos respondentes, tendo o auxílio educação o menor percentual (67\%). Já as recompensas não financeiras com exceção do trabalho em equipe e status/prestígio que foram escolhidas por $75 \%$ e $70 \%$ respectivamente, obtiveram percentuais superiores a $91 \%$. Ao questionar os pesquisados do seu estudo sobre a preferência entre recompensas financeiras e não financeiras, Alves et al. (2017) também concluíram que a maior parte dos respondentes escolheu as recompensas não financeiras, tais como reconhecimento e crescimento pessoal.

Quanto à análise fatorial exploratória, teste estatístico escolhido para a presente pesquisa, inicialmente esperava-se, por meio da aplicação do método de Análise do Componente Principal, utilizar todas as variáveis coletadas para extrair os fatores que retratassem a estrutura dessas variáveis. No entanto, após essa tentativa, foram encontrados cinco fatores, tendo sido observado que, apesar destes fatores explicarem mais de $65 \%$ da variação nos dados originais, atendendo o mínimo de 60\% sugerido por Hair et al. (2009), o teste de Kaiser-Meyer-Olkin (Measure of Sampling Adequacy - MSA), denominado como uma medida que quantifica o grau de intercorrelações entre as variáveis e a adequação fatorial, foi abaixo de 0,50, sendo que, de acordo com o autor, é considerado inaceitável. Como também se constatou que duas variáveis apresentaram carga fatorial (correlação entre uma variável original e seu fator) inferior a 0,50, que é o coeficiente mínimo para ser considerado como praticamente significante (Hair et al., 2009).

Em virtude do exposto, foram excluídas as duas variáveis, "desejo conduzir os negócios da minha família" e "ainda não sei o que fazer quando concluir o curso", que apresentavam cargas fatoriais baixas, sendo realizada uma segunda tentativa buscando atingir uma análise fatorial satisfatória. No entanto, após a execução novamente do teste, foi identificada uma terceira variável com baixa carga fatorial, "não pretendo trabalhar na área contábil”. Assim, após a retirada dessa terceira variável do modelo, foi gerado um novo resultado que apresentou quatro fatores, em que o teste de KMO resultou em um índice de 0,546, apresentando um teste de esfericidade Qui-Quadrado de Bartlett no valor de 108,581, com 45 graus de liberdade e 0,000 de significância. Além disso, todas as comunalidades (quantia de variância de cada variável explicada pelos fatores encontrados), apresentaram coeficientes acima de 0,516 e todas as cargas fatoriais foram superiores a 0,639, excedendo o mínimo recomendado por Hair et al. (2009). Na Tabela 8 são demonstradas as variáveis utilizadas, os fatores encontrados e suas cargas fatoriais. 
Tabela 8 - Análise fatorial (Rotação Varimax)

\begin{tabular}{|c|c|c|c|c|}
\hline \multirow[b]{2}{*}{ Variáveis } & \multicolumn{4}{|c|}{ Fatores } \\
\hline & $\begin{array}{l}\text { Profissional } \\
\text { liberal/ } \\
\text { Controller }\end{array}$ & Status & Estabilidade & $\begin{array}{l}\text { Trabalhar em } \\
\text { empresa de } \\
\text { terceiros }\end{array}$ \\
\hline $\begin{array}{l}\text { Pretendo montar um escritório de Contabilidade } \\
\text { depois de formado. }\end{array}$ & 0,802 & - & - & - \\
\hline Pretendo atuar como consultor contábil. & 0,765 & - & - & - \\
\hline Quero atuar como controller. & 0,656 & - & - & - \\
\hline Pretendo atuar como auditor interno/externo. & - & 0,846 & - & - \\
\hline Gostaria de atuar como perito contábil. & - & 0,688 & - & - \\
\hline $\begin{array}{l}\text { Quero prestar concurso em qualquer área depois de } \\
\text { formado. }\end{array}$ & - & - & 0,764 & - \\
\hline $\begin{array}{l}\text { Quero prestar concurso na área contábil depois de } \\
\text { formado. }\end{array}$ & - & - & 0,742 & - \\
\hline $\begin{array}{l}\text { Quero atuar no ensino, como professor ou pesquisador } \\
\text { da área contábil. }\end{array}$ & - & - & 0,639 & - \\
\hline $\begin{array}{l}\text { Quero trabalhar como contador em empresa de grande } \\
\text { porte. }\end{array}$ & - & - & - & 0,899 \\
\hline $\begin{array}{l}\text { Quero trabalhar como contador em empresa de } \\
\text { pequeno/médio porte. }\end{array}$ & - & - & - & 0,692 \\
\hline
\end{tabular}

Nota: Fonte: Dados extraidos do IBM SPSS statistics 23®.

Na Tabela 8 observa-se que foram utilizadas dez variáveis referentes às expectativas profissionais dos estudantes pesquisados e surgiram quatro fatores, sendo esses nomeados de acordo com o que cada variável representa. Os resultados obtidos e expostos por meio dessa tabela mostram que, a maioria das cargas fatoriais (60\%) apresenta coeficientes superiores a 0,70. Dessa forma seguindo o exposto por Hair et al. (2009) pode-se dizer que os fatores apresentados explicam $50 \%$ da variância das variáveis, o que de acordo com o autor indica uma estrutura bem definida, sendo a meta da análise fatorial.

Sobre a variância total explicada, na segunda tentativa observou-se que os fatores explicam aproximadamente $67 \%$ da variabilidade total dos dados, na qual individualmente, $18,74 \%$ das expectativas profissionais dos estudantes são explicadas pelo fator "Profissional liberal / controller", 17,93\% pelo "Status" da profissão, 16,58\% pelo desejo de "Estabilidade" e 14,20\% pela vontade de "Trabalhar em empresa de terceiros".

Nota-se, que dentre as variáveis que constituem o fator denominado "Profissional liberal/controller", a pretensão de montar um escritório de Contabilidade depois de formado apresenta maior carga fatorial, ou seja, essa é a variável que mais explica o fator. A intenção de atuar como auditor interno/externo possui maior carga fatorial no fator "Status", com isso, pode-se dizer que essa é a expectativa que mais explica o desejo de ter uma profissão que proporcione status. Isso é confirmado ao analisar separadamente as questões do questionário, visto que, dos 33 estudantes que escolheram como expectativa profissional ser auditor, mais de $75 \%$ indicaram o status como recompensa esperada. O fator "Estabilidade", prestar concurso na área contábil e em qualquer área depois de formado apresenta cargas fatoriais elevadas, ou seja, aqueles que pretendem ingressar na área pública buscam estabilidade. Já o desejo de trabalhar como contador em grandes empresas é a variável que melhor explica o quarto fator, denominado "Trabalhar em empresas de terceiros", com isso pode-se inferir que esse anseio seja em razão de se acreditar que empresas maiores remuneram melhor seus colaboradores.

Diante ao exposto, pode-se dizer que os estudantes que compuseram a amostra pesquisada, em sua maioria, apresentam expectativas profissionais que se relacionam com a intenção de ser profissional liberal, ter status e estabilidade no cargo exercido e trabalhar em empresas de terceiros.

\section{CONSIDERAÇÕES FINAIS}

Esta pesquisa objetivou examinar quais são as expectativas profissionais dos alunos que ingressaram em 2018, no curso de graduação em Ciências Contábeis, em uma IES pública, sendo que para alcançar este objetivo a mesma buscou: traçar o perfil dos estudantes, identificar quais recompensas profissionais são esperadas por eles e também verificar quais as áreas que os estudantes têm maior e menor interesse em atuar. 
O estudo descritivo, do tipo survey e com abordagem quantitativa, que teve como amostra 57 ingressantes no curso em 2018, analisou dados coletados no mês de outubro de 2018, a partir de um questionário aplicado de forma presencial que continha 42 questões fechadas, divididas em 12 questões de múltipla escolha e 30 assertivas com respostas obedecendo a uma escala do tipo Likert de cinco pontos. Em relação às técnicas de análise dos dados, utilizou-se da estatística descritiva e da Análise Fatorial Exploratória.

Sendo assim, os resultados indicam que a maior parte dos estudantes é do sexo feminino, possuem até 25 anos de idade e são solteiros. Em relação ao Ensino Médio, cursaram a modalidade regular, em escolas públicas, tendo concluído entre o ano de 2001 e 2017. Os estudantes, em sua maioria, trabalham com atividade remunerada, porém somente 10 respondentes exercem funções relacionadas à contabilidade. Cabe ressaltar também que $42 \%$ dos respondentes não trabalham.

O estudo evidenciou que, no tocante às expectativas profissionais, os estudantes demonstram uma preferência por cargos públicos, sejam eles na área contábil ou em outra área. Também se observou forte interesse em atuar como perito contábil, auditor interno/externo e contador em grandes empresas. Em relação às áreas de atuação pretendidas, identificou-se um maior interesse nas áreas financeira e de auditoria, sendo as áreas trabalhista e de contabilidade do agronegócio as que os estudantes demonstraram menor desejo em atuar.

Sobre as recompensas profissionais esperadas, percebe-se que os estudantes aspiram trabalhar em cargos que haja boa remuneração, que possam se realizar e crescer profissionalmente, assim como, ter estabilidade. Em adição, a análise fatorial demonstrou que as expectativas profissionais dos estudantes se referem à opção de atuar como profissional liberal, ter um cargo que proporcione status e estabilidade, e trabalhar em empresas de terceiros.

Observa-se, portanto, que os resultados desse estudo confirmam algo presente no conhecimento empírico dos indivíduos da área, mas que com os dados obtidos foram estatisticamente comprovados. Dessa forma, o estudo pode contribuir com os agentes interessados pela área contábil na divulgação da profissão e com a IES pesquisada e o seu corpo docente, visto que ao traçar um perfil do aluno ingressante é possível amenizar o desafio que as instituições enfrentam para conhecer seus estudantes, manter a qualidade do ensino e proporcionar a satisfação do corpo discente.

Na construção do estudo, algumas limitações foram constatadas, sendo elas: amostra reduzida, visto que a pesquisa foi realizada em uma única IES e que dos 100 alunos que ingressaram no curso em 2018, 57\% participaram da pesquisa, limitando-se os resultados a essa amostra e impossibilitando a generalização dos resultados, e o fato da teoria da expectativa não ter sido testada junto à amostra estudada.

Por fim, para pesquisas futuras, sugere-se dar continuidade à essa pesquisa, utilizando como amostra os ingressantes do curso em outras IES, inclusive instituições privadas. Dessa forma, podendo comparar os resultados obtidos, assim como, reaplicar essa pesquisa junto aos alunos concluintes, verificando assim, se há diferença nos resultados que foram encontrados ao pesquisar os ingressantes. Outra sugestão é realizar estudo similar em que a teoria da expectativa seja testada, verificando o efeito esforço sobre a expectativa dos estudantes, pois no presente estudo ela foi apenas citada.

\section{REFERÊNCIAS}

Alves, L. C., Silva, A. V. L, \& Oliveira, E. M. J. (2017). Motivação e recompensas: uma investigação com base nas Teorias da Hierarquia das Necessidades e da Expectativa. Revista Multidisciplinar e de Psicologia, 11(35), 325-340.

Bomtempo, M. S. (2005). Análise dos fatores de influência na escolha pelo curso de graduação em Administração: Um estudo sobre as relações de causalidade através da modelagem de equações estruturais. Dissertação de Mestrado, Centro Universitário Álvares Penteado, São Paulo, SP, Brasil.

Brandalise, L. T., \& Bertolini, G. R. F. (2013). Instrumentos de medição de percepção e comportamento - uma revisão. Rev. Ciênc. Empres. UNIPAR, 14(1), 7-34.

Castro, L. A. M. H. M., Nishimura, A. T., Silva, C. M., Madureira, B. M., \& Casado, T. (2007). Expectativas e satisfação dos alunos de graduação em administração da FEA-USP/SP em relação aos estágios. REGE Revista de Gestão, 14 (1), 61-76.

Costa, I. S. A., Salles, D. M. R., \& Fontes Filho, J. R. (2010). Influência das configurações organizacionais sobre valores no trabalho e preferências por recompensa. Rev. Adm. Pública, 44(6), 1429-1452.

Dutra, J. S. (2009). Gestão de pessoas: modelo, processos, tendências e perspectivas. São Paulo: Atlas.

Fávero, L. P., Belfiore, P. P., Silva, F. L., \& Chan, B. L. (2009). Análise de dados: modelagem multivariada para tomada de decisões. Rio de Janeiro: Elsevier.

Freitas, L. S., \& Freire, A. C. (2007). Fatores motivacionais na perspectiva de estudantes universitários, Qualit@s Revista Eletrônica. 6(1).

Instituição de Ensino Superior (IES) (2018). Informações sobre o curso de graduação em Ciências Contábeis. Recuperado em 12 abr. 2018, de http://contabeis.ies.br.

Gil, A. C. (2002). Como elaborar projetos de pesquisa. 4 ed. São Paulo: Atlas.

Hair, J. F., Black, W. C., Babin, B. J., Anderson, R. E., \& Tatham, R. L. (2009). Análise multivariada de dados. $6^{\circ}$ ed. Porto Alegre: Bookman.

Hipólito, J. A. M. (2004). Recompensas em Organizações que atuam no Terceiro Setor: Análise a partir de seus pressupostos orientadores. Tese de Doutorado, Universidade de São Paulo, SP, Brasil. 
Instituto Nacional de Estudos e Pesquisas Educacionais Anísio Teixeira (INEP) (2016). Censo Educação Superior 2016 . Recuperado em 20 abr. 2018, de http://portal.inep.gov.br/artigo/-/asset_publisher/B4AQV9zFY7Bv/content/mec-e-inep-divulgam-dados-do-censo-da-educacao-superior-2016/21206

Lagioia, U. C. T., Santiago, H. L., Gomes, R. B., \& Ribeiro Filho, J. F. (2007). Uma investigação sobre as expectativas dos estudantes e o seu grau de satisfação em relação ao Curso de Ciências Contábeis, Revista Contemporânea de Contabilidade, 4(8), 121-138.

Lei Complementar $n^{\circ} 101$, de 04 de maio de 2000. Estabelece normas de finanças públicas voltadas para a responsabilidade na gestão fiscal e dá outras providências. Recuperado em 20 abr., 2018, de http://www.planalto.gov.br/ccivil_03/Leis/LCP/Lcp101.htm.

Lobos, J. (1975). Teorias sobre a motivação no trabalho, Revista de Administração de Empresas, 15(2), 17-25

Marion, J. C., \& Santos, M. C. (2000). Os dois lados de uma profissão, Contabilidade Vista \& Revista, 11(2), 3-9.

Marion, J. C. (2008). Contabilidade Empresarial. 13º ed. São Paulo: Editora Atlas.

Marques, V. A., Dias, K. C. M., \& Silva, L. K. C. (2016). Expectativas profissionais dos estudantes de Ciências Contábeis em uma universidade de Minas Gerais, Percurso Acadêmico, 6(11), 107-127.

Maximiano, A. C. A. (1997). Administração de projetos: como transformar ideias em resultados. São Paulo: Atlas.

Miranda, C. S., Araújo, A. M. P., \& Miranda, R. A. M. (2015). Perfil e expectativas dos ingressantes do curso de ciências contábeis: um estudo em instituições de ensino superior do interior paulista, Revista de Gestão, Finanças e Contabilidade, 5(1), 4-20.

Nunes, C. A. (2014). Fatores determinantes na escolha dos estudantes do curso de Ciências Contábeis em instituições de ensino superior particulares da cidade de São Paulo. Dissertação de Mestrado, Fundação Escola de Comércio Álvares Penteado, São Paulo, SP, Brasil.

Panucci Filho, L. (2010). Dificuldades e perspectivas dos estudantes de ciências contábeis da Universidade Federal do Paraná segundo o perfil socioeducacional. Dissertação de Mestrado, Universidade Federal do Paraná, Curitiba, PR, Brasil.

Panucci Filho, L. (2011). Perspectivas profissionais dos estudantes de ciências contábeis, Revista Ciências Sociais em Perspectiva, 10(19), 10-19.

Peleias, I. R., Guimarães, P. C., Silva, D., \& Ornelas, M. M. G. (2008). Identificação do perfil profissiográfico de contabilidade requerido pelas empresas em anúncios de emprego na região metropolitana de São Paulo. BASE - Revista de Administração e Contabilidade da Unisinos, 5(2), 131-141.

Peleias, I, R., Nunes, C. A., Carvalho, R. F. (2017). Fatores determinantes na escolha do curso de Ciências Contábeis por estudantes de Instituições de Ensino Superior particulares na cidade de São Paulo. Revista Gestão Universitária na América Latina - GUAL, 10(3), 39-58.

Peleias, I. R., \& Nunes, C. A. (2015). Fatores que influenciam a decisão de escolha pelo Curso de Ciências Contábeis por alunos de IES na cidade de São Paulo. Revista Gestão Universitária na América Latina - GUAL, 8(3), 184-203.

Pinheiro, R. G. (2008). Fatores de escolha pelo curso de Ciências Contábeis - Uma pesquisa com os graduandos na capital e grande São Paulo. Dissertação de Mestrado, Fundação Escola de Comércio Álvares Penteado, São Paulo, SP, Brasil.

Pires, C. B. (2008). A formação e a demanda do mercado de trabalho do contador na região metropolitana de Porto Alegre - RS. Dissertação de Mestrado, Universidade do Vale do Rio dos Sinos, São Leopoldo, RS, Brasil.

Raupp, F. M., \& Beuren, I. M. (2013). Metodologia da Pesquisa Aplicável às Ciências Sociais. In: Beuren, I. M. (Org.). Como elaborar trabalhos monográficos em Contabilidade - Teoria e Prática. $3^{\circ}$ ed. São Paulo: Atlas.

Reis Neto, M. T., \& Marques, A. L. (2003). A satisfação dos profissionais de informática com os fatores motivacionais: Um estudo sobre expectativas e percepções. Revista de Negócios, 8(4).

Resolução CFC n. 560 de 28 de Outubro de 1983. Dispõe sobre as prerrogativas profissionais de que trata o artigo 25 do Decreto-Lei n. 9.295, de 27 de Maio de 1946. Recuperado em 02 jun 2018, de https://cfc.org.br/sisweb/sre/docs/RES_560.doc

Resolução CFC n. 898 de 22 de Fevereiro de 2001. Altera o $\S 1^{\circ}$ do art. $3^{\circ}$, da Resolução CFC n. 560/83. Recuperado de http://www. cfc.org.br/sisweb/sre/docs/RES_898.doc, em 12 mai 2018.

Resolução CFC n. 1486 de 22 de Maio de 2015. Regulamenta o Exame de Suficiência como requisito para obtenção de Registro Profissional em Conselho Regional de Contabilidade (CRC). Recuperado de http://www2.cfc.org.br/sisweb/sre/detalhes_sre.aspx?codigo=2015/001486, em 12 mai 2018.

Robbins, S. P. (2005). Comportamento organizacional. $11^{\circ}$ ed. São Paulo: Pearson Prentice Hall.

Robbins, S. P., Judge, T. A., \& Sobral, F. (2010). Comportamento organizacional: teoria e prática no contexto brasileiro. Tradução Rita de Cássia Gomes. $14^{\circ}$ ed. São Paulo: Pearson Prentice Hall.

Scarpin, M. A., \& Almeida, W. C. (2010). Graduandos de Ciências Contábeis e sua carreira profissional, Revista de Estudo Contábeis, 1(1), 24-37.

Schmidt, P., Ott, E., Santos, J. L., \& Fernandes, A. C. (2012). Perfil dos alunos do curso de ciências contábeis de instituições de ensino do sul do Brasil, Revista ConTexto, 12(21), 87-104.

Silveira, D. T. \& Córdova, F. P. (2009). A pesquisa científica. In: Gerhardt, T. E; Silveira, D. T. (Org.) Métodos de pesquisa. Porto Alegre: Editora da UFRGS.

Simões, A. J. C. (2008). Motivações e expectativas profissionais dos estudantes de enfermagem. Estudo numa escola da área de Lisboa. Dissertação de Mestrado, Universidade Aberta, Lisboa, Portugal.

Vergara, S. C. (2003). Gestão de pessoas. São Paulo: Atlas. 